\title{
First evidence of a food poisoning outbreak due to staphylococcal enterotoxin type E, France, 2009
}

A Ostyn (a.ostyn@afssa.fr) ${ }^{1}$, M L De Buyser ${ }^{1}$, F Guillier ${ }^{1}$, J Groult' ${ }^{1}$, B Félix ${ }^{1}$, S Salah², G Delmas ${ }^{3}$, J A Hennekinne ${ }^{1}$

1. AFSSA-LERQAP (French Food Safety Agency, Food Quality and Food Processes Research Laboratory), European Union Reference Laboratory for Coagulase Positive Staphylococci including Staphylococcus aureus, Maisons-Alfort, France 2. Health Emergency Mission Directorate General for Food, Ministry of Food Agriculture and Fishery, Paris, France

3. InVS, Infectious diseases department, national institute for public health surveillance, Saint Maurice, France

Citation style for this article: Ostyn A, De Buyser ML, Guillier F, Groult J, Félix B, Salah S, Delmas G, Hennekinne JA. First evidence of a food poisoning outbreak due to staphylococcal enterotoxin type E, France, 2009. Euro Surveill. 2010;15(13): pii=19528. Available online: http://www.eurosurveillance.org/ViewArticle. aspx?Articleld $=19528$

This article has been published on 1 April 2010

At the end of 2009, six food poisoning outbreaks caused by staphylococci were reported in France. Soft cheese made from unpasteurised milk was found to be the common source of the outbreaks. Staphylococcal enterotoxin type E was identified and quantified in the cheese using both official and confirmatory methods of the European Union Reference Laboratory (EU-RL). To our knowledge, this is the first report of food poisoning outbreaks caused by staphylococcal enterotoxin type $E$ in France.

\section{Introduction}

Staphylococcal food poisoning is one of the most common food-borne diseases worldwide [1] resulting from the ingestion of staphylococcal enterotoxins preformed in food by enterotoxigenic strains of coagulase-positive staphylococci, mainly $S$. aureus. As staphylococcal enterotoxins are heat stable, they may be present in food when S. aureus are absent [2]. Moreover, not all strains of $S$. aureus are enterotoxigenic. Therefore, a conclusive staphylococcal food poisoning diagnosis is mainly based on the detection of staphylococcal enterotoxins in food. To date, 21 staphylococcal enterotoxins have been described: staphylococcal enterotoxin (SE) A (SEA) to SEIV all possess superantigenic activity whereas only some (SEA to SEI, SER, SES and SET) have been proven to be emetic [3]. These toxins are produced by enterotoxigenic strains of coagulasepositive staphylococci (mainly S. aureus) in food with high protein content.

In October and November 2009, six household staphylococcal food poisoning outbreaks were notified in six French metropolitan départements. During the investigation, which was carried out by interviewing cases specifically focussing on food consumed, it became clear that a soft cheese made from unpasteurised cow milk was the likely common and single source of these outbreaks as all cases had eaten the same cheese. Cheese samples were available from six outbreaks and the staphylococcal food poisoning diagnosis was confirmed through (i) the high count of coagulase-positive staphylococci, (ii) the detection of staphylococcal enterotoxin $E$ in the incriminated cheese type and (iii) the detection of the see gene in coagulase-positive staphylococci isolates from the suspected cheese samples.

\section{Methods \\ Epidemiological data}

All the epidemiological data concerning these outbreaks (number of cases, symptoms, location, type of potentially incriminated food) were collected by interviews or questionnaires by the local health authorities (DDASS). At the same time, the tracing of incriminated food was performed by the local services of the French Ministry of Food, Agriculture and Fishery.

Counts and characterisation of coagulasepositive staphylococci strains

Coagulase-positive staphylococci were counted in suspected cheese samples by laboratories involved in food surveillance using the standard method EN ISO 6888 part 2 as described in the relevant European Union (EU) legislation [4]. Coagulase-positive staphylococci isolates were tested for enterotoxin genes by PCR targeting the $S$. aureus $23 \mathrm{~S}$ rRNA gene and biotyped as described by Kerouanton et al. [5]. The isolates were tested for sea-e, seg-j, ser and sep genes using two multiplex PCR assays according to the procedures of the EU Reference Laboratory (EU-RL) for coagulasepositive staphylococci. The isolates were also typed by pulsed-field gel electrophoresis (PFGE) according to Kerouanton et al. [5].

Sample preparation and immunoenzymatic detection of staphylococcal enterotoxins The detection of staphylococcal enterotoxin types A to $E$ was performed according to the EU-RL screening method for coagulase-positive staphylococci [6]. This method consists of an extraction step followed by dialysis concentration and an immuno-enzymatic detection using the Vidas SET2 kit (BioMérieux, Marcy l'Étoile, France). Staphylococcal enterotoxins were quantified 
according to the EU-RL confirmatory method which uses a quantitative indirect sandwich enzyme-linked immunosorbent assay (ELISA) in order to separate and quantify staphylococcal enterotoxins type A to E [6].

\section{Results}

\section{Epidemiological information}

Between 29 October and 14 November 2009, six outbreaks comprising 23 cases with gastrointestinal symptoms were reported through the network for mandatory notification of food-borne outbreaks, in six French districts (Figure 1).

\section{FIGURE 1}

Geographic distribution of food poisoning outbreaks due to staphylococcal enterotoxin type E, France, OctoberNovember 2009 ( $\mathrm{n}=23)$

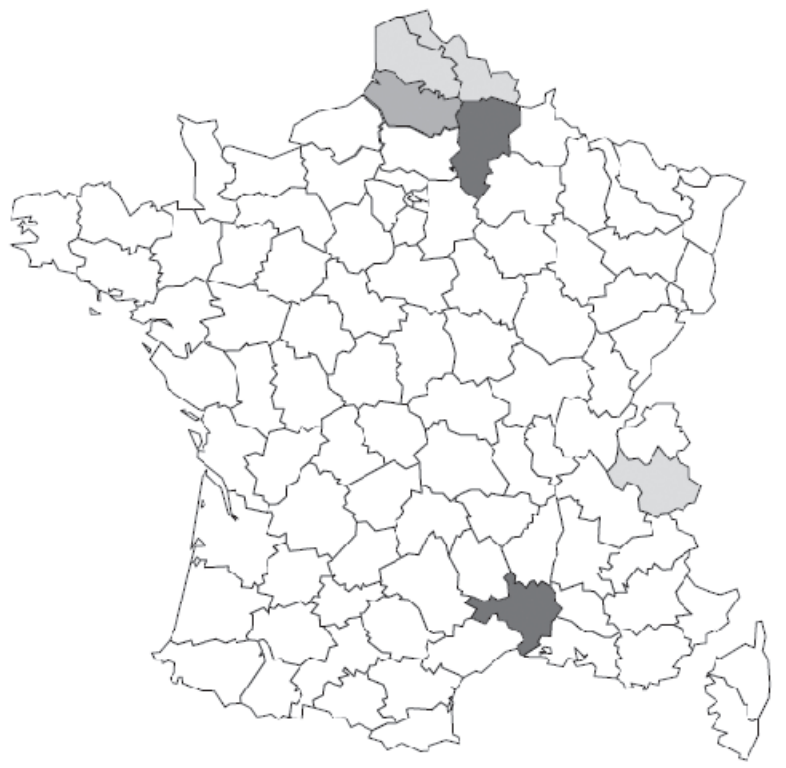

Number of cases per French metropolitan département

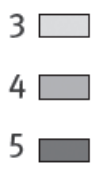

A total of 23 persons of 26 persons who had consumed cheese (attack rate $88.5 \%$ ) suffered from nausea, vomiting, abdominal cramps and diarrhoea, in some cases associated with fever. The period between the ingestion of the cheese and the onset of symptoms ranged from $1 \mathrm{~h} 15$ to $8 \mathrm{~h}$. The investigation, performed by the Directorate General for Food of the Ministry of Agriculture using interviews and/or questionnaires, showed that a soft cheese made from unpasteurised cow milk distributed in supermarkets was the most likely source of food poisoning. Three cheese batches (I, II and III), produced during weeks 40 and 41 (2009) by the same producer and coming from a single milk storage tank, were involved in the six outbreaks (Table 1).

\section{Counts and characterisation of coagulase- positive staphylococci strains}

More than $1.5 \times 10^{5}$ colony-forming units (CFU) of coagulase-positive staphylococci/g were isolated from cheese samples from the three batches involved in the outbreaks. No cheese samples were available for outbreaks four and five. No coagulase-positive staphylococci could be detected in the cheese sample from outbreak six as this cheese had been heated before consumption. Five to ten coagulase-positive staphylococci isolates from each batch were analysed (total number $n=20$ ) and characterised. The isolates were all typed as $S$. aureus by a species-specific $23 \mathrm{~S}$ rRNAtargeted PCR test. All were found to carry the see gene and none of the other se genes tested (Table 2, Figure 2). Four isolates were further characterised. They harboured a non-host specific biotype profile, K- $\beta-C V: C$, named $\mathrm{NHS}_{5}$ at the EU-RL, and showed the same PFGE pattern which was distinct from all other PFGE patterns available in the EU-RL database, including the pattern from the reference SEE-producing strain, FRI 326 (data not shown).

Using immunoassays to detect staphylococcal enterotoxins in samples The EU-RL screening method using the qualitative and combined Vidas SET2 test detected SEA to SEE in the three cheese batches involved in the outbreaks.

\section{TABLE 1}

Epidemiological details of food poisoning outbreaks due to staphylococcal enterotoxin type E, France, October-November 2009 (n=6 outbreaks)

\begin{tabular}{|l|c|c|c|c|c|}
\hline Outbreak & Date & $\begin{array}{c}\text { Number } \\
\text { ill/symptomatic }\end{array}$ & Symptoms & $\begin{array}{c}\text { Period between inges- } \\
\text { tion of cheese and } \\
\text { onset of symptoms }\end{array}$ & Cheese batch involved \\
\hline 1 & 3 November & $3 / 4$ & AC, D, V & $1 \mathrm{~h} 15$ & $\mathrm{III}$ \\
\hline 2 & 5 November & $5 / 5$ & AC, D, V, F & $8 \mathrm{~h}$ & $\mathrm{II}$ \\
\hline 3 & 4 November & $4 / 4$ & $\mathrm{~N}, \mathrm{AC}, \mathrm{D}, \mathrm{V}, \mathrm{F}$ & $6 \mathrm{~h}$ & $\mathrm{I}$ \\
\hline 4 & 8 November & $3 / 3$ & $\mathrm{~N}, \mathrm{AC}, \mathrm{D}, \mathrm{V}$ & $6 \mathrm{~h}$ & $\mathrm{II}$ \\
\hline 5 & 29 October & $3 / 4$ & $\mathrm{AC}, \mathrm{D}, \mathrm{V}$ & $2 \mathrm{~h} 45$ & $\mathrm{II}$ \\
\hline 6 & 14 November & $5 / 6$ & AC, D, V & $2 \mathrm{~h} 30$ & $\mathrm{III}$ \\
\hline
\end{tabular}

AC: abdominal cramps; D: diarrhoea; F: fever; N: nausea; V: vomiting 
Moreover, the EU-RL confirmatory method detected and quantified SEE amounts ranging from 0.36 to higher than $1.14 \mathrm{ng} / \mathrm{g}$, including the cheese sample from outbreak six where coagulase-positive staphylococci could not be detected (Table 2).

\section{Discussion}

As unpasteurised cow milk cheese was the common and single food associated with all outbreaks according to the epidemiological investigation, they were obviously incriminated in the food poisonings described here. Moreover, the aetiological agent could be determined because of (i) the symptoms of the cases, (ii) the high number of coagulase-positive staphylococci recovered from remains of cheese incriminated in the outbreak and (iii) the amounts of staphylococcal enterotoxins recovered from cheese samples. In outbreak number six, the cheese had been cooked before consumption, explaining why no coagulase-positive staphylococci were recovered from this sample. Indeed, the coagulase-positive staphylococci were killed by the heat treatment whereas the staphylococcal enterotoxins,

\section{FIGURE 2}

Detection of the see gene on $10 \mathrm{~S}$. aureus isolates from the cheese responsible for food poisoning outbreaks due to staphylococcal enterotoxin type E, France, OctoberNovember 2009

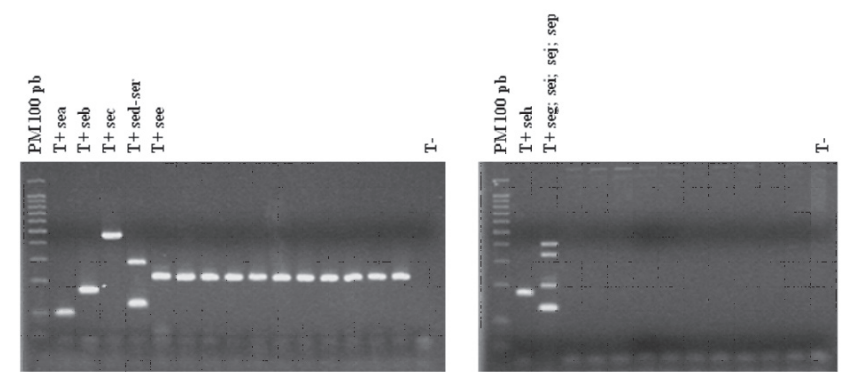

Left: positive controls for sea to see and ser genes followed by the 10 tested isolates and negative control.

Right: positive controls for seg to sej and sep genes followed by the 10 tested isolates and negative control. known to be heat resistant, remained active to cause a food poisoning outbreak and were actually detected in this sample.

The only type of staphylococcal enterotoxin detected in all food samples was SEE. This finding was reinforced by the fact that all tested coagulase-positive staphylococci isolates were found to carry a single se gene, see. This is the first staphylococcal food poisoning outbreak where SEE has been confirmed as the causative agent in France. The involvement of SEE seems to be also rare in other countries: to our knowledge, this staphylococcal enterotoxin has been associated to only few outbreaks. They were reported between 1960 and 1971 in USA [7] and in the United Kingdom (UK) [8] and a single case was analysed later on in the UK [9]. Otherwise, the most frequently staphylococcal enterotoxin type involved in staphylococcal food poisoning outbreaks worldwide is SEA, associated or not with other staphylococcal enterotoxins [2]. This is in agreement with the results observed by Kerouanton et al. [4] showing that SEA was the most frequently found (69.7\%) among 31 French staphylococcal food poisoning outbreaks analysed between 1981 and 2002; out of 178 coagulase-positive staphylococci isolates tested for se genes, the most frequent gene was sea followed by sed, seg, sei and seh. The genes seb and sec were less frequent, and see gene was not found.

Moreover, the present study appears to be the first one where SEE was not only detected but also quantified in the food vehicle. In outbreak number six, SEE amount found in cheese sample was equal to 0.45 $\mathrm{ng} / \mathrm{g}$. Considering that symptomatic persons ingested a portion of about $200 \mathrm{~g}$ (data obtained from the cases interviewed in outbreak number six), the total amount of ingested SEE could be estimated to $90 \mathrm{ng}$. This dose is in accordance to those estimated in previous staphylococcal food poisoning outbreaks where SEA and/or SEA/SEH were confirmed as the causative agents [1].

\section{TABLE 2}

Analysis of cheese samples and coagulase-positive staphylococci isolates from cheese, France, October-November 2009

\begin{tabular}{|c|c|c|c|c|c|c|}
\hline \multirow[b]{2}{*}{ Outbreak number } & \multirow[b]{2}{*}{ Cheese batch number } & \multirow{2}{*}{$\begin{array}{c}\text { Microbiological test } \\
\text { in cheese samples } \\
\text { CPS counts } \\
\text { CFU/g of food } \\
\text { sample }\end{array}$} & \multicolumn{2}{|c|}{ PCR tests on CPS isolates } & \multicolumn{2}{|c|}{$\begin{array}{l}\text { SEA to SEE detection tests in cheese } \\
\text { samples }\end{array}$} \\
\hline & & & $\begin{array}{l}\text { S. aureus } \\
\text { 23S rRNA gene }\end{array}$ & $\begin{array}{c}\text { sea to sej } \\
\text { and } \\
\text { ser, sep genes }\end{array}$ & $\begin{array}{l}\text { Qualitative } \\
\text { detection }^{\mathrm{b}}\end{array}$ & $\begin{array}{l}\text { Quantitative detection for } \\
\text { SEE in food sample } \\
\text { (ng/g) }\end{array}$ \\
\hline 1 & III & $>1.810^{7}$ & Detected $(n=5)$ & see $(n=5)$ & positive & $>0.92(n=1)$ \\
\hline 2 & II & $21.510^{5}$ & Detected $(n=5)$ & see $(n=5)$ & positive & $>1.14(\mathrm{n}=11)$ \\
\hline 3 & I & $>7.510^{5}$ & Detected $(n=10)$ & see $(n=10)$ & positive & $0.36(n=2)$ \\
\hline $6^{e}$ & III & $<10^{2}$ & \multicolumn{2}{|c|}{ Not relevant } & positive & $0.45(n=1)$ \\
\hline
\end{tabular}

PCR: polymerase chain reaction; CPS: coagulase-positive staphylococci; SEA: staphylococcal enterotoxin A; SEE: staphylococcal enterotoxin

E; CFU: colony forming units.

a The results of PCR assays for se genes are shown in Figure 2

${ }^{b}$ Global qualitative detection for SEA to SEE using Vidas SET 2 kit

'Confirmatory quantitative method for SEA to SEE (SEA to SED not detected)

d Mean of the quantitative results

e Cheese cooked before consumption 
Considering that the coagulase-positive staphylococci isolates from the contaminated cheese samples showed the same se gene pattern, the same $\mathrm{NHS}_{5}$ biotype, the same PFGE profile and also the same antibiogram (data not shown), it can be considered that the same $S$. aureus strain involved in the six outbreaks came from the same origin. However, due to the non host-specific biotype detected, it was not possible to determine whether the contamination was from human, bovine or environmental source. In a previous French study [10], this $\mathrm{NHS}_{5}$ biotype was found in $8.5 \%$ of $2,021 \mathrm{~S}$. aureus isolates from five types of raw milk cheeses; it was at the fourth rank after bovine-, $\mathrm{NHS}_{4}$ - and NHS3-biotypes among the 20 distinct biotype profiles observed, indicating that its presence is not unusual in this food category.

Finally, this study illustrates that the French national surveillance system is able to detect rare events. The staphylococcal food poisoning outbreaks linked to SEE ingestion described here were quickly identified through a close collaboration between the Health Emergency Mission, the National institute for public health surveillance and the EU-RL with laboratories involved in food surveillance for coagulase-positive staphylococci and staphylococcal enterotoxins and the good cooperation of all parties involved. The rapid recall of contaminated cheese batches by the French Ministry of Food, Agriculture and Fishery prevented further cases. Due to the distribution across Europe of the incriminated type of cheese, the EU Member States were informed by the Rapid Alert System for Food and Feed (RASFF) reference 2009.1567 https://webgate. ec.europa.eu/rasff-window/portal/index.cfm?event $=$ n otificationDetail\&NOTIF_REFERENCE=2009.1567.

\section{Acknowledgements}

The authors would like to thank Bertrand Lombard for reading the manuscript, Muriel Marault for her input in the implementation of the new PFGE protocol, Thi Trinh Tam Dao, Sabine Messio, Sylvie Pairaud and Isabelle Papinaud for their technical assistance.

\section{References}

1. Hennekinne JA, Brun V, De Buyser ML, Dupuis A, Ostyn A, Dragacci S. Innovative contribution of mass spectrometry to characterise staphylococcal enterotoxins involved in food outbreaks. Appl Environ Microbiol. 2009;75(3):882-4.

2. Balaban N, Rasooly A. Staphylococcal enterotoxins. Int J Food Microbiol. 2000;61(1):1-10.

3. Ono HK, Omoe K, Imanishi K, Iwakabe Y, Hu DL, Kato H, et al. Identification and characterization of two novel staphylococcal enterotoxins types S and T. Infect Immun. 2008;76(11):4999-5005.

4. European Commission. Commission Regulation 1441/2007 of 5 December 2007. Official Journal of the European Unuion. 2007;L322:12-29. Available from: http://eur-lex.europa.eu/ LexUriServ/LexUriServ.do?uri=0J:L:2007:322:0012:0029:EN: PDF

5. Kérouanton A, Hennekinne J.A, Letertre C, Petit L, Chesneau O, Brisabois A et al. Characterization of Staphylococcus aureus strains associated with food poisoning outbreaks in France. Int J Food Microbiol. 2007;115(3):369-75.
6. Hennekinne JA, Ostyn A, Guillier F, Gohier M, Messio S, Dragacci $S$ et al. Interlaboratory validation of the Vidas SET2 detection kit for an use in official controls of staphylococcal enterotoxins detection in milk products especially low-fat cheeses. J AOAC Int. 2007;90(3):756-64.

7. Bergdoll ML, Borja CR, Robbins RN, Weiss KF. Identification of Enterotoxin E. Infect Immun. 1971;4(5):593-5.

8. Morris CA, Conway HD, Everall PH. Food-Poisoning due to staphylococcal enterotoxin E. Lancet, 1972:2(7791):1375-6.

9. McLauchlin J, Narayanan GL, Mithani V, O’Neil G. The detection of enterotoxins and toxic shock syndrome toxin genes in Staphylococcus aureus by polymerase chain reaction. J Food Prot. 2000;63(4):479-88.

10. De Buyser ML, Lapeyre C. [Inventaire des souches isolées de cinq types de fromage au lait cru : les méthodes d'analyse, le dénombrement de Staphylococcus aureus, la détection des toxines]. In "Compte-rendu de la journée Thématique Staphylocoques”. ARILAIT-Recherches, 30 Mars 1995. Paris. p.67-72. [French] 